\title{
DECADENCE DESCRIPTION OF THE LEXICON UNDERSTANDING IN THE PART OF THE BATAK TOBA'S BODY LANGUAGE BY TEENAGERS IN BATAM CITY
}

\author{
Dairi Sapta Rindu Simanjuntak ${ }^{1}$ \\ Universitas Putera Batam (UPB), Batam, Indonesia \\ saptadairi@gmail.com \\ Yessie Aldriani ${ }^{2}$ \\ Universitas Putera Batam (UPB), Batam, Indonesia \\ aldrianiyessie@gmail.com
}

\begin{abstract}
Indonesia is known as the country "Bhinneka Tunggal Ika" that means unity in diversity also symbolizes the unity of the NKRI which is strong and sturdy even though it consists of different backgrounds. Ethnic language is one type of diversity that Indonesian have. In heterogeneous societal structures, language clashes are an unavoidable phenomenon especially in big cities. Language attitudes are tested especially in groups of teenagers. If the speech community does not have a strong language attitude, it will certainly have an impact on language retention. One of the ethnic groups that experienced in this phenomenon was the Batak Toba ethnic group as the urban people in Batam. The aim of this study is to describe the occurrence of the understanding of the Batak Toba adolescents in Batam City in terms of lexicon mastery related to body parts. To get the data on the level of understanding of respondents, as many as 45 lexicon data were tested through a questionnaire to respondents aged 12-18 years who numbered 50 people, and the results were further described. The results showed that there was a decrease in understanding in the group of adolescents towards the body language lexicon of the Batak Toba language. The majority of respondents only heard of the lexicons but did not know the references. This is evidence of the gap in ethnic language understanding between parents and adolescents. This understanding gap is a result of the lack of learning or use of ethnic language in the family. If this condition is then left alone, it is certain that the lexicon will become extinct because it will disappear from the entity's understanding of the speaker.
\end{abstract}

Keywords: decandence deskription understanding, lexicon part of body, Batak Toba language

\section{INTRODUCTION}

The development of technology and society have mobilized the use of a language. The parents have prefered to teach Indonesian and foreign languages to their children to communicate. This will raise the new problem for their children that is the existence of ethnic languge will lead to the extinction because of the entity of very low utilization in society. This also has determined the decadency of the ethnic language. The phenomenon has occured in all ethnics, one of them is the ethnic language of Batak Toba.

The indications of decadence are seen clearly in every activity of communication. Ironically, the condition has occured in all across generations. Surely, this situation is very frightening, moreover for the observers of ethnic language. Unbelievable, the native speakers of a language who basically the speakers should keep and do all of their attempts to defend the identity, an emblem as well as their true identity. Nowaday, it 
is very easy to find a generation of an ethnic group, however they have no knowledge at all against their ethnic language. Such people are called no longer having the ethnic identity. Now, only a few of many generations show the ethnic identities in communication activities in some places such as, in supermarket, place of worship, in neighbourhood, in public area, and many other places, eventhough their ability are also not very good, but at least there is an effort to learn and show who themselves.

Another factor that cause of the language shift is, immigration. If an ethnic group come to live in a foreign country and blended with the local ethnic and another newcomer ethnics, so that the language shift occurred. In this condition. The langauge behaviour of the speakers are examined. The newcomer groups are going to forget some of their languages and to be required to acquire the local ethnic language in order to adapt with a new social environment.

It is reasonable to occure in multicultural society. Moreover, if in the social environment, there is one group which dominate or majority. The next condition occurred is the majority group will affect the minority group. It means, in this case the mayority language will directly affect the minority group language. It's impossible for the minority to affect the mayority. It means the mayority group language will affect directly the minority language since the dominant language used in the environment is the majority group language which has more speakers. For example, the residents who live in one neighborhood with a different ethnic background. There are Javaness, Batak, Melayu, Sundaness, Flores and the rest. The majority group is Javaness around $70 \%$.
Therefore, Javaness language will dominate. Inevitably, the other ethnic group must adapt themselves and indirecty, they are forced to learn the majority group language. It is done in order to tied a social relationship well. However, the other side, there is one thing must be bet that is to defend their ethnic language, become more difficult to be fought since the less space for the other ethnic to use their ethnic language (Simanjuntak, 2015).

Bilingualism of community language is not the only problem that can cause the language shift. It also occures through a generation transition and relates to some generations. The language decandence may not occure to a generation. This change occures in the wide contex that is regeneration. It can be concluded that the decadence can be examined by using of language intra generation not by comparing between one invidual to another. From the observation, it can be observed the words which are still inherited and which become extinct.

There are some previous researches which talked about the change or language shift, the first, the reseach tittle is Bilingualism, Language Shift and The Corresponding Expansion of Spatial Cognitive Systems (Meakins, Jones, \& Algy, 2015) that analyzed the change of society structure impact to language decadence. The result of this research was the change of lingustic system causes the cognitive change. Traditionally, Gurindji people (Australia) use English more right now. One of the variable is education. The second research is Transition Space Medium Repair: Language Shift Talked Into Being (Gafaranga, 2011) that the finding was the Rwanda community member in Belgium achieved the language change. The language shift occurred from monolingual Kiryawanda 
to French language in the process of interaction with children.

Lexicon is the language domain which experienced the fastest change, for example the lexicon of the body parts (LPB). The change can be observed from the traditional life change to the modren one, the gap of knowledge from parents to children. (Simanjuntak, 2015b). As the proofs of the decadence are hurum (face), dila ( (tongue), ipon (tooth), pardompahan (forehead), pusok ( ?), gonting (wrist), lau (batock), botohon (arm), and many others lexicons which are seldom used by Batak Toba Speakers (BTS)especially the teenagers. Clearly, this condition will threaten the existing of the lexicons among MBT life. It can be concluded that the existence of lexicon will be eroded because of lack of using the LBT in the daily communication and can be more fatal that is leading to the extinction since the missing of lexicon concept from the speaker understanding. Such conditions are the main reasons of doing the reseacrh in order to record the occurrence of the decandence of understanding of LBT BBT by teenager speakers in Batam.

\section{LITERATURE REVIEW}

2.1. Sosiolinguistics

Language in the broad meaning is the human communication tool. However,the language as the communication tool must be able to reflexct the thought in order to transmit the proper message well, and the language also must be universal or agreed so that every language speakers understand the used code. Based on this, the language is called as the social indications since there is another factor out of the languge which influence in the language use. One of the out of language factor is social. The social factor become the main factor of language variation. One of the causes of language variatio is the various social cause (Chaer dan Agustina, 2004).

Sociolinguistics is one of the branches of macro linguistics. Sociolingustics is the intern-dicipline science between sociology and linguistics, two empiris sciences which relate very (see Chaer and Agustina, 2004). Sociology is tied to scientific study about human being in a society and the social process in a society as well. By using the study, it will be known how the human being adapt in their environment, interact, place themselves in accordance with the place in a society. Meanwhile, linguistics is the study about a language or science that a language is study object. It can be concluded that sociolinguistics is the study about a language in relation to the language use in society.

\subsection{Language Shift}

The occurrence of langauge shift is the language use problem by the speakers that pointed out as the cause of immigration or the movement of a community language to the other one. Immigration or the movement can occurre because the destination region offers the better life hope than the previous one. It presents a reality that must be faced by the newcomer of language community because the society of destination region surely has the different language so that the language shift occurres. One of the examined language is the language which has majority speakers, will influence the language behaviour of newcomer speakers. Inevitably, the newcomer society must adapt with the language of destination region society.

In communicating with fellow groups of origin, they are still able to maintain their native language, 
however, when they interact with the destination region society, it is impossible for them using their native language. They must slowly learn the local language that uncounciously will lead to the lower entity of their native language use, consequently it can result in loss of comprehension context on the next generation. For the first they come and use one language that is ethnic language, after living for a long time in the destination region, slowly they become monolingual society, by using the native language and the local language.

Then after a long period, to the next generation of third or fourth they have to go back into monolingual society though the mastered language is not the native language, but the destination region language/local language.

\subsection{Lexicon}

Lexicon is language component that memuat information about the word meaning. Lexicon is also meant as the words list and the word form in a language with the meaning and function. Lexicon is also defined as vocabulary; the language component which memuat information about the meaning of the word use in a language; the richness of word in a language.

Lexicon includes a component which informs about the word in a langauge like semantics, syntax, morphology and phonology, meanwhile for the vocabulary is stressed on the richness of word which owned by someone or a language (Sibarani, 1997: 4). Similar to Sibarani, Booij's ideas (2007:16) said that "the lexicon specifies the properties af each word, its phonological form, its morphological adn syntactis properties, and meaning."

It can be concluded from the explanation above that lexicon is the language component of which contains all the information about the meaning of the word in such behavior of semantically, syntactically, morphologically, and phonologically or the vocabulary are stressed to the richness of the word.

\section{THE RESEACH METHOD}

The method used in this research is descriptive method. Method used in this study is the descriptive method. The corpus data research sourced from the results of the tested survey respondents of 50 ethnic batak toba teenagers around 12 to18 aged years. The survey offered three options the answer categories those are 'know category', 'do not know ever hear category', do not know never heard of category. From the survey measurement was obtained the percentage of their level of understanding youth groups of respondents to list the lexicon. After the survey data measurement of the level understanding of teenagers obtained and this were converted to percentages based on each category. Then, the presentage data was described how the teenager understanding decadence on the lexicon of body parts of batak Toba in Batam.

\section{RESULT AND DISCUSSION}

This section is presented a description of the teenager understanding decadence on the lexicon of parts of the body of Batak Toba language. The first lexicon sitarupon 'hair'. For this lexicon only 1 respondent for Know (K), 10 respondents for Do Not Know, Ever Heard (DNK,EH) and 39 respondents for Do Not Know, Never Heard (DNK,NH). Later, the lexicon is indeed very rare mentioned in daily conversation. Moreover the lexicons are included in a category of courtesy and euphemistic lexicon. The use of a 
lexicon is dominant in the context of utterances among the old people or people who concerned with the courtesy context utterances in the speaking process. The lexicon 'hair' in Batak Toba language (BTL) is known by lexicon sitarupon and obuk. There is not the differences of meaning between both lexicon, but differ gramatically. The lexicon meaning for sitarupon is more polite than obuk however, it does not mean that the meaning of obuk is negative. The teenagers know obuk more than sitarupon because it is more familiar among them. The older speakers group also often use the lexicon obuk so that the teenager understand the obuk lexicon than than sitarupon lexicon.

The lexicon simajujung is BTL of 'head'. It is about $34 \%$ of teenager respondent for Know (K) category. This figure indicates that at least 17 respondents are already proficient in right meaning and the referents of a lexicon simajujung as well. Besides simajujung, in BTL there is another name for head namely ulu. There are the differences in value of sense between the two lexicons. Lexicon ulu is very rude and discourtesy. The use of a lexicon $u l u$ signifies the speakers morals. Nevertheless, in fact the lexicon is often mentioned in daily utterances by Batak Toba community. Meanwhile, for the category of Do Not Know, Ever Heard (DNKEH) total respondent is $42 \%$. They have only heard the lexicon but they are not aware of the referent. It also applies to the third category of DNK NH totally $24 \%$, is smaller than the first and second categories. Respondents in this category are those who always use Indonesian in their daily life either in a family or school environment so that their comprehension for the lexicon is none.
Sipareon lexicon is comprehended by $2 \%$ respondents for Know $(\mathrm{K})$ category. It means only 1 respondent who knows the referent of this lexicon. This lexicon is also known by pinggol in Batak Toba Langage (BTL). Yet, similar to the other lexicon, the interpretation for this lexicon is lower than sipareon. If the young people use pinggol to the older, it is really uncivilized. The comparison between DNK,EH category totally $38 \%$ with DNK,NH totally $58 \%$ is very drastic. The low level of manifestation of using the lexicon in daily utterances to be the cause of the low level of teens' understanding of the lexicon. The use of foreign language and Indonesian is also the reason of the teens knowing and using the lexicon referent as telinga.

Simalolong is mata (eyes) in Indonesian comprehended by $48 \%$ of respondents. Eventhough, all the respondent is not included in $\mathrm{K}$ category however, the percentage indicates the use of the lexicon is still high enough. One of the reason is there is not any other lexicon to name sense of vision. The category of DNK,EH respondents are those who just hear the lexicon but do not find out the referents of the lexicon. While the category of DNK,NH respondents are those who do not have any experience about the lexicon not only in family environment but also in neighborhood .

Parnianggoan is BTL for nose. Igung is another lexicon for parnianggoan of BTL. As the previous lexicons, parnianggoan is the most appropriate lexicon to mention the sense of human olfactory. Yet, majority of teenagers are categorized as DNK,NH for using parnianggoan.The entity of using the lexicon igung is higher or more productive in the community 
utterances although the lexicon is clearly lacking cordiality.

The next lexicon is simanghudap for mouth however, this lexicon is more popular than the lexicon baba eventhough the meaning is very rude thus, it is usually used for curse. In daily communication, the use of simanghudap is very low in the environment of both parents and especially the teenagers. It is about $20 \%$ of respondents included in DNK,EH category and $80 \%$ for the DNK,NH one. The low level of manifestation of the lexicon use has resulted the absence of the teenager respondents in the category of ' $\mathrm{K}$ '.

Bohi is the only lexicon for face in BTL thus this lexicon become more productive in society. The productive use of the lexicon in family and society impact on mastery of the respondents of the lexicon. It is evidenced by the results of the questionnaire showed nearly $100 \%$ of respondents exist in the category of ' $\mathrm{K}$ '. Next, the lexicon rungkung is the only naming for 'neck' in BTL. However, the use of this lexicon is not as productive as the lexicon bohi so that the total of respondents who comprehend this lexicon is not as high as bohi although the majority of respondents is ' $\mathrm{K}$ '. At least there are $34 \%$ respondens who are included in DNK,NH category. Those who included in this category are the group who use Indonesian as the first language.

The lexicon isang, is only comprehended by $12 \%$ of respondent for ' $\mathrm{K}$ ' category. The presentage for this lexicon is the fewest than another category. In Indonesian isang is dagu. There is not another name for isang in BTL yet, the problem is the productivity of using it. The teenagers are more familiar with Indonesian so that it is no wonder if they often use dagu although they are speaking their region language.In addition, some of them have just heard the lexicon but they are not knowledgeable about the referent of the lexicon.

The next lexicon is pardompahan for forhead. Based on the questionare result no one of respondents is included in ' $\mathrm{K}$ ' category. One of the reasons is as a result of an error understanding by the older against this lexicon. Many BTL speakers are not able distinguish between bohi (face) and pardompahan (forhead). The low language proficiency of region langauge impact on the low use of this lexicon in daily life.

Sirampuson is the BTL lexicon that is very rare used. Even the old people seldom use this lexicon. Although daily activity is very high with this lexicon, but it is not directly proportional to its use in society because the Batak Toba community are more familiar with Indonesian language jari or jari-jari (finger) although they are using their region language. The fact has resulted in the absence of teenagers respondents who are categorized as ' $\mathrm{K}$ '. The majority of respondents is in the category DNK,NH. (Do Not Know, Never Heard). This condition is certainly worrying because it can led to the loss of the lexicon from the lexicon list of BTL in the future.

Lexicon inong ni sirampuson or ibu jari in Indonesian (thumb) has similar problem with the previous one that is unproductive so that this lexicon has been missing from the speakers understanding specially the teenagers. Even the percentage of the teenagers' comprehension to the lexicon of inong ni sirampuson is more worrying than the previous one.

The lexicon botohon is one of BTL lexicons that is almost extinct. Only a few of of people know this lexicon. Botohon in Batak Toba ethnic is often 
used as a name, however it is called lengan in Indonesian language. This lexicon is almost never heard even among the older people. This is why all respondents are categorized as DNK,NH. Another lexicon which almost extinct is simangido or tangan in Indonesian (hand). This lexicon is also categorized unproductive in society due to know Indonesian language more.

The next lexicon are simanjungkit or kelingking', situalang or jari manis', and sijagoa or 'jari tengah', the following words in English are little finger, ring finger and middle finger and the lexicons are almost exctint. It is almost never heard in society utterance of Batak Toba language. The phenomenon is also the cause of loosing the lexicon from the teenager's comprehension. The low level of interest in learning an ethnic language and the strong influence of a foreign language become the further reasons for the community to know more Indonesian language. The other BTL lexicon such as singku or siku in Indonesian (elbow) is also comprehended by a few parts of teenagers around 24\%, while the majority has not comprehended this lexicon and its referent as well. The lexicon hurum or rahang in Indonesian or jaw is only known by 5 people or $10 \%$ of respondents. The community of BTL also knows the referent of lexicon in Indonesian language. The low entity of using this lexicon have an impact on the understanding level of its speakers especially the younger generation.

The understanding decadence of teenagers also occures in the lexicon abara which means shoulder. The BTL speakers almost never mention this lexicon particularly in the city. Therefore, no surprises then that all respondents of teenagers are categorized as DNK,NH. It means that there is not the lexicon in the understanding entity of the teenagers or it can be said that the lexicon have been lost from their generation. Only a very small percentage and the number of parents still have contact with the lexicon. The lexicon andora, or dada in Indonesian or chest is still mastered by the respondents because it is still active used in the community. Nevertheless some teenagers are not knowledgeable about this lexicon through lack of the use of ethnic language or the low understanding of parents against the region language resulting in lack of the lexicon that can be passed on to their children especially in family environment. However, the lexicon utok-utok or otak in Indonesian or brain in English is still a productive lexicon. We often hear the BTL community mention this lexicon in daily communication not only among parents but also across generations. Some of respondents who do not understand the lexicon are those who use ethnic language very low.

Lexicon abas or lidah in Indonesian or tongue cannot be mastered by any teenager. Another lexicon but different sense is dila. It has negative meaning, it is not polite language. Dila is oftten used as a curse or refer to an animal tongue. Eventhough, in fact most of community use dila in communication and it does not raise a conflict because of choosing inappropriate word, still the lexicon does not reflect the courtesy of the speakers if it is spoken to refer to a human tongue. While the lexicon ipon or gigi in Indonesian or tooth is still familiar enough for the teenager group so no wonder that many teenagers still understand the lexicon. Actually, besides ipon, the BTL community often mention tooth with ngingi that is really very rude than ipon, The lack of 
understanding of older speakers to the lexicon ipon inevitably, the use of lexicon ngingi can be understood and accepted in certain contexts considered as indifference. The following lexicons are still one place in a mouth those are suratan or gusi in Indonesian or gum and hola or langit-langit in Indonesian or palate. Based on the questionares result, none of teenagers know the lexicons. For them the lexicona are the first time to be heard. In the daily communication, either intern parents and the teenagers or among them, they name in Indonesia langauge. This condition has proved that this lexicon has been extinct from the understanding of teenagers right now.

The lexicon butuha bolon or lambung in Indonesian or is gastric understood by half of the respondents. The finding is enough to prove that the lexicon is still very productive even though some teenagers categorized as DNK. Next, the lexicon siubeon or perut in Indonesian or stomach is only understood by $6 \%$ of respondents. It is very few and in critis zone. Generally, the community mention with butuha, while it has impolite meaning or very low than siubeon. The low using of the lexicon in community have an impact on the lack of speakers' understanding to this lexicon. It is proved that $84 \%$ of respondents are categorized DNK.(Do Not Know).

The lexicon ate-ate or hati in Indonesian or liver is one of a lexicon by very high understanding. This is not surprising considering the lexicon is very productive in the community both across generations and intra-generation. Yet, there are several persentages of teenagers who are categorized as DNK. Those are the teenagers who live among their family that BTL becomes the second language. The following lexicon is pusu-pusu or jantung in Indonesian or heart. The understandong of respondents to the lexicon is quite balanced intern category. None of category is nominant yet, there is still one category which the most total of understanding that is $\mathrm{K} 38 \%$. While $\mathrm{DNK}, \mathrm{EH}$ is $36 \%$ and DNK,NH is $26 \%$. Those are included in both categories are those who is mastery Indonesian language more dominant than their region langauge. Beside that the influences of multicultural society also grind their understanding against the ethnic language.

The shifting of understanding also occures on the lexicon butuha raja or usus in Indonesian or colon. Actually, this lexicon is quite familiar, yet the fact is only $20 \%$ of respondents. The majority of respondents is the second and the third category. This shows that the lexicon is actually still exist in a society, however the gap occures because the parents prefer to use Indonesian langauge when they mention this lexicon to the young generation. The lack of parent's motivation to introduce the ethnic language to their children has resulted the gaps in the understanding. The lexicon rak or paruparu in Indonesian or lungs is only productive in the context of custom. In daily communication, this lexicon is seldom mentioned. This is why all the respondents are in the category of DNK,NH. The parents have not given a chance to the teenagers to get involved in customs activity and indeed, in the other side the young generation are not interested in learning such things because they think that their way of thinking and life style have changed from traditional to modern life. That is why this lexicon has missed the understanding of teenagers.

The following lexicon holi-holi or tulang in Indonesia or bone is only comprehended by $74 \%$ of respondents. 
This lexicon is still exist and productive in community. The high of the respondents' comprehension on the lexicon due to the other name for bone in BTL. Holi-holi does not only refer to the meaning of bone itself but also all kind of bone including uga or the animal bone. Although in fact there are some respondents who are categorized as DNK however, it is enough to be the proof that this lexicon has not missed yet and still survived. There are some of respondents who do not understand the lexicon are those who often use Indonesian language as the result of the multicultural social structure that encourage them to learn Indonesian language. The category of the respondents for the lexicon aru-aru is DNK,NH, totally 44\%. Actually, the entity of using this lexicon in community is high enough however the low entity of using the ethnic language between the parents and their children become the reason of the low understanding of teenagers against the lexicon that have an impact of missing their understanding concept. Some of respondents who have ever heard but do not know the referent of the lexicon is the result of the lack of interest and parental supervision and also the teenagers themselves to learn the ethnic language.

The following facts of the teenagers' understanding decandence are garda penis , amburat buttocks, palak palms/sole of foot, tambihul knees, natu male genitalia, and parbungaan female pubic. From the questioner result, all the respondents are the category of DNK,NH. It means that the teenagers have not experienced with this lexicon. Virtually, they know the referent of the lexicon but they name it in Indonesian language. In the context of daily conversation, the lexicon is almost never mentioned by the older speakers, especially the teenagers. The influence of a foreign language and social structure have made the lack of their understanding of the lexicon. This condition have an impact on the missing lexicon from the speakers' understanding especially the teenagers. If this condition continues, it can be confirmed that the lexicon will be extinct.

The lexicon hae-hae or paha in Indonesian or thigh is used for mentioning not only the human thigh but also for any kinds of species. Eventhough in BTL, there in not other lexicon for hae-hae, the fact is only around $44 \%$ of respondents categorized ' $\mathrm{K}$. It is not half of the total respondents. They are the group of the more active teenagers who use or hear the ethnic langauge so that their understanding of the lexicon still higher. While there are around 30\% categorized DNK,EH that have only heard but they do not know the referent. Similar to the category of DNK, NH totally $26 \%$ who do not have any experiences related to the lexicon. Truly, they know its referent however, they have no knowledge about the name of referent in their ethnic languge. They master Indonesia language as the result of the multicultural community social condition and they feel that there is not any requirement to learn ethnic language.

The lexicon bitis calf is understood by $70 \%$ of respondents. The high understanding of the teenagers towards the lexicon because the lexicon is still exist in its speaker community. The use of the lexicon is also productive. Beside that, the similarity of fonetic between the ethnic language and Indonesian langauge also determine the high understanding of them on the lexicon. When they hear the lexicon bitis, the referent in their mind is calf. However, 
there are some teenagers who have no knowledge about it. Some of them have only ever heard but do not know the referent, and some other have never heard it at all. The number is not significant, but it can be confirmed that the lexicon has missed from their understanding.

The lexicon simanjojak, foot is dominant in the category of DNK,EH. Only a few of the respondents is in ' $\mathrm{K}$ ' category. Actually the problems are the same as other previous lexicons. In fact, the teenagers understand the referent of the lexicon yet in Indonesian language. There is another lexicon for foot that is pat. The meaning of pat is lower and less polite in the community of Batak Toba utterance. Pat is used to mention any kinds of foot including animal foot such cat's foot pat ni huting, leg's foot pat ni meja and many others. The use of pat is more productive than simanjojak, eventhough it cannot be used for mentioning human foot. This misunderstanding causes the teenagers'comprehension of the lexicon is more crushed.

The last lexicon is dugul-dugul knee. The understanding of teenagers on this lexicon is high in the category of ' $\mathrm{K}$ ' because there is not any other lexicon for knee in BTL. Beside that, the use of the lexicon is productive enough in the community. However, It cannot be denied that some percentage of respondents have only heard but they do not know its referent, some of them do not understand the lexicon at all. This condition is as the result of the low entity of using the ethnic language in neighborhood and family so that they master the lexicons in Indonesian language.

\section{CONCLUSION}

Based on the description of the teenagers' understanding on the BTL as the previous explanation which has experienced the decandence process. The main problem of the phenomena is the gap of ethnic language understanding between parents and teenagers. The gap of the understanding is the result of the lack of learning or using the ethnic language between the parents and the teenagers. It also leads to low feeling of love, feeling of pride, and curiosity and ethnic languages learning. The language community must realize that the ethnic language is identity, emblem, and the regional identity which cannot be missed in community. The heritage is the assets which must be preserved. The parents must encourage their children to learn the ethnic language if they do not want their children miss their identity in the future. The parents need to involve the young generation in customary activity, and it is possible to do it. To change the paradigm of customary activity only for the parents to be done as soon as possible. The young generation must change their mind set as well. The mastery of regional identity is not a primitive one. When a lot people learn foreign languages, at the time we must awake from our sleep that everybody can master any foreign languages so that it will very difficult to find someone who still maintain his identity. To learn a culture and also a foreign language are not prohibition. Those are good things to be done to win the competition globally specially today the change and the development are very difficult to be avoided. However, It has to be used as an opportunity to introduce our culture as our regional identity in order to be known broadly.

This phenomenon has encourage the language and book organization to formulate a statement of the followings 'prioritize Indonesian language, learn a foreign language, and keep up the local 
language. It is to maintain the dignity of the language from the influence of the current global change.

\section{REFERENCES}

Booij, Geert. (2007). The Grammar of Words: An Introduction to Linguistics Morphology (Edisi kedua). New York : Oxford University Press Inc.

Chaer, Abdul dan Leoni Agustina. (2004). Sosiolinguistik: Perkenalan Awal. Jakarta: Rineka Cipta.

Gafaranga, J. (2011). Transition space medium repair: Language shift talked into being. Journal of Pragmatics, 43(1), 118-135. https://doi.org/10.1016/j.pragma.2 010.08.001

Meakins, F., Jones, C., \& Algy, C. (2015). Bilingualism, language shift and the corresponding expansion of spatial cognitive systems. Language \& Communication, 1-13. https://doi.org/10.1016/j.langsci.20 15.06.002

Simanjuntak, D. S. R. (2015a). Penerapan Teori Antropolinguistik Modern (Competence, Performance, Indexicality, \& Partisipation) Dalam Umpasa Budaya Batak Toba. Jurnal Basis, 2 no 2, 8. Retrieved from http://ejournal.upbatam.ac.id/index .php/basis/article/view/407/265

Simanjuntak, D. S. R. (2015b). Perubahan Fungsi Sosioekologis Leksikon Flora Bahasa Pakpak Dairi. Jurnal Linguistik, 12 No 1 , 35-53.

(2017). Flora Lexicon of Pakpak Dairi, Proceeding International Conference On Language, Literature, And Art In New Media
And Technologies And Public Spaces UIN Sunan Gunung Djati Bandung, 26 Oktober 2017, hlm. 490-503. 
